\section{Tobacco-Related Exposures}

\section{Introduction}

Tobacco contains more than 2,500 chemical constituents, many of which are known human carcinogens. Tobacco smoking produces both mainstream smoke, which is drawn through the tobacco column and exits through the mouthpiece during puffing, and sidestream smoke, which is emitted from the smoldering tobacco between puffs. Chewing tobacco and snuff are the two main forms of smokeless tobacco used in the United States. Tobacco smoking, environmental tobacco smoke, and smokeless tobacco were first listed (separately) in the Ninth Report on Carcinogens (2000). The profiles for each of these substances and exposure circumstances, which are listed (separately) as known to be a human carcinogen, follow this introduction.

\section{Tobacco Smoking}

CAS No.: none assigned

Known to be a human carcinogen

First listed in the Ninth Report on Carcinogens (2000)

\section{Carcinogenicity}

Tobacco smoking is known to be a human carcinogen based on sufficient evidence of carcinogenicity from studies in humans.

\section{Cancer Studies in Humans}

Tobacco smoking has been shown to cause cancer of the lung, urinary bladder, renal pelvis, oral cavity, pharynx, larynx, esophagus, lip, and pancreas in humans (IARC 1986). The risk of death from lung cancer increases with increasing duration of smoking and with increasing numbers of cigarettes smoked. Smoking cessation avoids the increased risk associated with continued smoking. The carcinogenic effects of tobacco smoke are increased in individuals with certain predisposing genetic polymorphisms (i.e., which code for different forms of the metabolic enzyme microsomal monooxygenase).

Since tobacco smoking was first listed in the Ninth Report on Carcinogens in 2000, the International Agency for Research on Cancer has reevaluated the evidence for the carcinogenicity of tobacco smoking and tobacco smoke (IARC 2012). They concluded that there was sufficient evidence in humans that cigarette smoking causes cancer of the nasal cavity and accessory sinuses, stomach, colorectum, liver, kidney (body and pelvis), ureter, and uterine cervix and ovary (mucinous) and myeloid leukemia, in addition to the tissue sites mentioned above, and that there was limited evidence that it causes breast cancer in women. IARC also concluded that there was sufficient evidence that parental smoking causes hepatoblastoma in children and limited evidence that it causes childhood leukemia (particularly, acute lymphoblastic lymphoma).

\section{Cancer Studies in Experimental Animals}

Tobacco smoke has been shown to cause cancer in several species of experimental animals. Inhalation exposure to cigarette smoke caused cancer of the larynx in hamsters and increased the incidence of benign and/or malignant lung tumors in rats. In mice exposed to cigarette smoke by inhalation, the increased incidence of lung tumors was not statistically significant; the data for dogs were insufficient for evaluation. Co-exposure of rodents to tobacco smoke and other carcinogens (polycyclic aromatic hydrocarbons or radon daughters) resulted in more respiratory-tract tumors than did exposure to either substance alone. Dermal exposure to cigarette-smoke conden- sates caused skin tumors in mice and rabbits, and topical application of cigarette-smoke condensates to the lining of the mouth (oral mucosa) caused lung tumors and lymphoma in mice. Intrapulmonary injection of cigarette-smoke condensate caused lung tumors in rats (IARC 1986, 1987).

\section{Studies on Mechanisms of Carcinogenesis}

Individual chemical components of tobacco smoke have been shown to be carcinogenic in humans and experimental animals. Tobacco smoke or tobacco-smoke condensates caused cell transformation, mutations, or other genetic damage in a variety of in vitro and in vivo assays. The urine of smokers was shown to be mutagenic, and there is evidence that the somatic cells of smokers contain more chromosomal damage than those of nonsmokers (IARC 1986). Lung tumors from smokers contained a higher frequency of mutations in the p53 tumor-suppressor gene and the K-ras proto-oncogene than did tumors from nonsmokers; most of the mutations were $\mathrm{G}$ to $\mathrm{T}$ transversions (Vineis and Caporaso 1995, IARC 2004).

\section{Properties}

Mainstream tobacco smoke is produced at a high temperature $\left(900^{\circ} \mathrm{C}\right)$ in the presence of oxygen; it is drawn through the tobacco column and exits through the mouthpiece during puffing. Tobacco pyrolysis products are formed both during smoke inhalation and during the interval between inhalations (NRC 1986). The composition of tobacco smoke is affected by many factors, including the tobacco product, properties of the tobacco blend, chemical additives, smoking pattern, $\mathrm{pH}$, type of paper, filter, and ventilation.

Approximately 4,000 chemicals have been identified in mainstream tobacco smoke, and some researchers have estimated that the actual number may exceed 100,000; however, the currently identified compounds make up more than $95 \%$ of the total mass of mainstream smoke. These include carbon oxides, nitrogen oxides, ammonia, hydrogen cyanide, volatile aldehydes and ketones, nonvolatile alkanes and alkenes, benzene, hydrazine, vinyl chloride, isoprenoids, phytosterols, polynuclear aromatic compounds, alcohols, nonvolatile aldehydes and ketones, phenols, quinones, carboxylic acids, esters, lactones, amines and amides, alkaloids, pyridines, pyrroles, pyrazines, $N$-nitrosamines, metals, radioactive elements, agricultural chemicals, and chemical additives. The nicotine in tobacco is addictive and produces several pharmacological and toxicological effects. Mainstream smoke contains more than 400 individual gaseous components, with nitrogen (58\%), carbon dioxide (13\%), oxygen (12\%), carbon monoxide (3.5\%), and hydrogen $(0.5 \%)$ predominating. Particulates are formed in the range of 0.1 to $1 \mu \mathrm{m}$ in diameter. Particulate-phase components account for approximately $8 \%$ of mainstream smoke, and other vapor-phase components for approximately $5 \%$ (IARC 1986, Vineis and Caporaso 1995).

\section{Use}

Smoking was introduced to Europe from the Americas in the middle of the 16th century and then spread throughout the world. Currently, the primary source for tobacco smoke is cigarettes. Pipes, cigars, bidis, and other forms are used less frequently (IARC 1986). The use of pipes and cigars was more prevalent in the 18th and 19th centuries, but usage shifted from these products to cigarettes after 1910. Cigarette consumption levels in the United States increased from 2.5 billion in 1900 to 640 billion in 1981, but had declined to 420 billion by 2002 (ALA 2008). In the 2002 National Survey on Drug Use and Health, $30.4 \%$ of persons in the United States aged 12 or older reported any tobacco use in the past month; $26.0 \%$ reported use of cigarettes, $5.4 \%$ use of cigars, and $0.8 \%$ use of pipes (SAMHSA 2003). 


\section{Production}

Tobacco has been an important economic agricultural crop since the 1600s. North and Central America produce the largest quantity. Nicotiana tabacum is the most common species of tobacco used in cigarettes, but $N$. rustica also is used in some areas. In the manufacture of smoking tobacco, the tobacco leaf material is manipulated by physical and chemical methods, some of which are intended to reduce the yields of toxic agents and tars in smoke. The tobacco is fine cut and wrapped in paper for consumption. Generally, cigarettes are a blend of various flue-cured grades, burley, Maryland, and oriental tobaccos (IARC 1986). From 1987 to 1997, the annual U.S. tobacco harvest ranged from 1.19 billion pounds to 1.79 billion pounds (USDA 1993, 1998). In 2017, the United States imported over 7 billion cigarettes and exported over 2 billion (USITC 2018).

\section{Exposure}

Smokers are exposed primarily by inhalation; however, some exposure may occur through absorption of chemicals present in the tobacco or tobacco smoke directly through the lining of the mouth and gums.

Although tobacco use in the United States has declined, a significant number of people use tobacco products. U.S. cigarette consumption increased from 2.5 billion in 1900 to 640 billion in 1981, but declined to 420 billion by 2002 (ALA 2008). Between 2002 and 2017, the National Survey on Drug Use and Health reported that the percentage of people using tobacco generally declined, from $30.4 \%$ to $22.4 \%$ for persons aged 12 or older who reported any tobacco use in the past month. Reported use of cigarettes declined from $26.0 \%$ to $17.9 \%$, and use of cigars declined from $5.4 \%$ to $4.6 \%$ for use of cigars, but use of pipes did not change (remaining 0.8\%) (SAMHSA 2003, 2018). From 1965 to 2017, the estimated number of adult smokers in the United States decreased 31.5\%, to 34.3 million (Wang et al. 2018). Over the same period, the percentage of adults who smoked cigarettes declined 67\%, from 42.4\% to 14.0\% (ALA 2019a). From 1997 to 2017 , smoking among youths decreased $75.8 \%$, from $36.4 \%$ to $8.8 \%$ (ALA 2019c). Per-capita consumption of cigarettes also has declined from a peak of 4,345 in 1963 to 1,017 in 2016 (a 76.6\% decrease) (ALA 2008, Drope and Schluger 2019). From 1974 to 2017, the percentage of adult smokers who smoked fewer than 15 cigarettes per day more than doubled (from $31.6 \%$ to $65.3 \%$ ), while the percentage of heavy smokers (who smoked over 24 cigarettes per day) declined by $78.6 \%$ (from 25.3\% to 5.4\%) (ALA 2019b). From 2005 to 2016, the percentage of ever-smokers (persons who had smoked at least 100 cigarettes during their lifetimes) who quit smoking increased $16.1 \%$ (from $50.8 \%$ to 59\%) (Jamal et al. 2018). Strategies in the United States for reducing exposure to tobacco smoke include goals for increasing tobaccouse cessation and reducing the number of new smokers (PHS 2008).

The use of tobacco products varies with gender, age, education, and culture. The prevalence of smoking has always been higher in men than women. In 1965 , over half $(51.9 \%)$ of adult men smoked, compared with $33.9 \%$ of women. Smoking prevalence peaked at $67 \%$ for men in the 1940s and 1950s and at $44 \%$ for women in the 1960s. By 2017 , smoking prevalence had declined to $15.8 \%$ for men and $12.2 \%$ for women. Smoking prevalence was highest in the 25-to-44 age group from 1965 to the mid 1990s. However, smoking increased in the 18-to-24 age group during the 1990s, reaching a peak in 1997 (28.7\%), while prevalence continued to decrease in the 25-to-44 age group. By 2017, smoking had declined to $10.4 \%$ for the 18 -to- 24 age group and $16.1 \%$ in the 25 -to- 44 age group, and was highest in the 45-to-64 age group (16.5\%). Smoking among high-school students increased during the first half of the 1990s, but has since declined, from $36.4 \%$ in 1997 to $8.8 \%$ in 2017. As of 2017, smoking prevalence by ethnic group was as follows: $24.6 \%$ of American Indians and Alaska Natives, $15.3 \%$ of non-Hispanic whites, $15.1 \%$ of non-Hispanic blacks, 9.9\% of Hispanics, and 7.0\% of Asians (ALA 2019a,c).

\section{Regulations}

\section{Executive Order 13058}

It is the policy of the executive branch to establish a smoke-free environment for Federal employees and members of the public visiting or using Federal facilities and, therefore, the smoking of tobacco products is prohibited in all interior space owned, rented, or leased by the executive branch of the Federal Government, and in any outdoor areas under executive branch control in front of air intake ducts.

Federal Aviation Administration (FAA, Dept. of Transportation)

Smoking is prohibited for all scheduled flights within the United States.

Food and Drug Administration (FDA, an HHS agency)

Oral contraceptives must contain a package insert concerning the increased risks associated with tobacco smoking and oral contraceptive use.

Federal Trade Commission (FTC)

All cigarette packages and advertisements for cigarettes must contain a label statement on the risks of smoking.

Advertising of cigarettes on radio and television is banned.

Occupational Safety and Health Administration (OSHA, Dept. of Labor)

OSHA has developed regulations that prohibit cigarette smoking in certain areas.

\section{References}

ALA. 2008. Trends in Tobacco Use. American Lung Association. http://www.notontobacco.com/media/ files/TREND_TOBACCO_JULY_08-1.pdf.

ALA. 2019a. Adult smoking rate by sex, race, and age. American Lung Association. Unpublished data, received $1 / 30 / 19$.

ALA. 2019b. Heavy smoking by sex, race, age, and education. American Lung Association. Unpublished data, received 1/30/19.

ALA. 2019c. HS smoking rate trend by sex and race. American Lung Association. Unpublished data, received 1/30/19.

Drope J, Schluger NW, eds. 2019. Per-capita cigarette consumption by country. In The Tobacco Atlas. American Cancer Society and Vital Strategies. https://files.tobaccoatlas.org/wp-content/uploads/2018/03/ consumption-map.csv. Last accessed: 3/7/19.

IARC. 1986. Tobacco Smoking. IARC Monographs on the Evaluation of Carcinogenic Risk of Chemicals to Humans, vol. 38. Lyon, France: International Agency for Research on Cancer. 421 pp.

IARC. 1987. Tobacco smoke. In Overall Evaluations of Carcinogenicity. IARC Monographs on the Evaluation of Carcinogenic Risk of Chemicals to Humans, suppl 7. Lyon, France: International Agency for Research on Cancer. pp. 359-362.

IARC. 2004. Tobacco Smoking and Involuntary Smoking. IARC Monographs on the Evaluation of Carcinogenic Risks to Humans, vol. 83. Lyon, France: International Agency for Research on Cancer. 1452 pp.

IARC. 2012. Tobacco smoking. In Personal Habits and Indoor Combustions. IARC Monographs on the Evaluation of Carcinogenic Risk of Chemicals to Humans, vol. 100E. Lyon, France: International Agency for Research on Cancer. pp. 43-211.

Jamal A, Phillips E, Gentzke AS, Homa DM, Babb SD, King BA, Neff LJ. 2018. Current cigarette smoking among adults — United States, 2016. Morbid Mortal Wkly Rep 67(2): 53-59.

PHS. 2008. Treating Tobacco Use and Dependence: 2008 Update. U.S. Public Health Service. http://www. surgeongeneral.gov/tobacco/treating_tobacco_use08.pdf.

SAMHSA. 2003. Results From the 2002 National Survey on Drug Use and Health: National Findings. Substance Abuse and Mental Health Services Administration. http://www.oas.samhsa.gov/nhsda/2k2nsduh/ Results/2k2Results.htm\#toc.

SAMHSA. 2018. Key Substance Use and Mental Health Indicators in the United States: Results from the 2017 National Survey on Drug Use and Health. Substance Abuse and Mental Health Services Administration. https://www.samhsa.gov/data/sites/default/files/cbhsq-reports/NSDUHFFR2017/NSDUHFFR2017.pdf. USDA. 1993. Field Crops: Final estimates 1987-1992. U.S. Department of Agriculture. http://usda.mannlib. cornell.edu/usda/nass/SB982/sb896.txt.

USDA. 1998. Field Crops: Final estimates 1992-1997. U.S. Department of Agriculture. http://usda.mannlib. cornell.edu/usda/nass/SB982/sb947.pdf.

USITC. 2018. USITC Interactive Tariff and Trade DataWeb. United States International Trade Commission. http://dataweb.usitc.gov/scripts/user_set.asp and search on HTS no. 2402200000.

Vineis P, Caporaso N. 1995. Tobacco and cancer: epidemiology and the laboratory. Environ Health Perspect 103(2): 156-160

Wang TW, Asman K, Gentzke AS, Cullen KA, Holder-Hayes E, Reyes-Guzman C, Jamal A, Neff L, King BA. 2018. Tobacco product use among adults — United States, 2017. Morbid Mortal Wkly Rep 67(44): 1225-1232. 


\section{Environmental Tobacco Smoke}

CAS No.: none assigned

Known to be a human carcinogen

First listed in the Ninth Report on Carcinogens (2000)

\section{Carcinogenicity}

Environmental tobacco smoke is known to be a human carcinogen based on sufficient evidence of carcinogenicity from studies in humans.

\section{Cancer Studies in Humans}

Studies support an association of environmental (passive or secondhand) tobacco smoke with cancer of the lung and, in some cases, the nasal sinus (CEPA 1997). Evidence for an increased cancer risk from environmental tobacco smoke stems from studies examining nonsmoking spouses living with individuals who smoke cigarettes, exposure of nonsmokers to environmental tobacco smoke in occupational settings, and exposure to parents' smoking during childhood (IARC 1986, EPA 1992, CEPA 1997). Many epidemiological studies, including large population-based case-control studies, have demonstrated increased risks for developing lung cancer following prolonged exposure to environmental tobacco smoke. A meta-analysis of epidemiological studies found an overall increase in risk of $20 \%$ for exposure to environmental tobacco smoke from a spouse who smokes. Increased risk of lung cancer appears to be most strongly related to exposure to environmental tobacco smoke from spousal smoking or exposure in an occupational setting.

Exposure of nonsmokers to environmental tobacco smoke has been demonstrated by detection of nicotine, respirable smoke particulates, tobacco-specific nitrosamines, and other smoke constituents in the breathing zone, and by measurements of a nicotine metabolite (cotinine) in the urine. However, there is no good biomarker for cumulative past exposure to tobacco smoke, and all of the information collected in epidemiological studies determining past exposure to environmental tobacco smoke relies on estimates that may vary in their accuracy (recall bias). Other suggestions of systematic bias have been made concerning the epidemiological information published on the association of environmental tobacco smoke with cancer. These include misclassification of smokers as nonsmokers; factors related to lifestyle, diet, and other exposures that may be common to couples living together and that may influence lung-cancer incidence; misdiagnosis of cancers that metastasized from other organs to the lung; and the possibility that epidemiological studies examining small populations and showing no effects of environmental tobacco smoke would not be published (publication bias).

Three population-based case-control studies (Brownson et al. 1992, Stockwell et al. 1992, Fontham et al. 1994) and one hospitalbased case-control study (Kabat et al. 1995) addressed potential systematic biases. Each of the three population-based studies found an increased risk from prolonged exposure to environmental tobacco smoke of a magnitude consistent with previous estimates. The hospital-based study found similarly increased risk, but the results were not statistically significant. The potential for publication bias has been examined and dismissed (CEPA 1997). Some meta-analyses found no increased risk of lung cancer among nonsmokers exposed only in occupational settings; however, when the meta-analyses included only higher-quality studies, an excess risk was found (Wells 1998). Thus, factors related to chance, bias, and/or confounding have been adequately excluded, and exposure to environmental tobacco smoke is established as causally related to human lung cancer.
Since environmental tobacco smoke was first listed in the Ninth Report on Carcinogens in 2000, the International Agency for Research on Cancer has concluded that there is limited evidence in humans that exposure to second-hand tobacco smoke causes cancer of the larynx and pharynx (IARC 2012).

\section{Studies on Mechanisms of Carcinogenicity}

Sidestream smoke and mainstream smoke contain many of the same chemical constituents, including at least 250 chemicals known to be toxic or carcinogenic. As discussed in the profile for Tobacco Smoking (above), exposure to primarily mainstream smoke through active tobacco smoking has been shown to cause cancer of the lung, urinary bladder, renal pelvis, oral cavity, pharynx, larynx, esophagus, lip, and pancreas in humans. Environmental tobacco smoke, sidestream smoke, sidestream smoke condensate, and a mixture of sidestream and mainstream smoke condensate have been shown to cause genetic damage. Increased concentrations of mutagens were found in the urine of humans exposed to environmental tobacco smoke, and lung tumors from nonsmokers exposed to environmental tobacco smoke had mutations in the p53 tumor-suppressor gene and K-ras proto-oncogene similar to those found in lung tumors from smokers (IARC 2004).

\section{Cancer Studies in Experimental Animals}

In mice exposed for five months to filtered and unfiltered environmental tobacco smoke (defined as a mixture of $89 \%$ sidestream and $11 \%$ mainstream smoke) and allowed to recover for four months in filtered air, lung tumor incidence and multiplicity were significantly increased; however, tumor incidence was not significantly increased in mice exposed for five months without a recovery period (Witschi et al. 1997a,b). Other studies indicate that inhaled cigarette smoke and topically applied cigarette-smoke condensate can cause cancer in experimental animals, and that the condensate of sidestream smoke is more carcinogenic to the skin of mice than equivalent amounts (by weight) of mainstream-smoke condensate. Since environmental tobacco smoke was first listed in the Ninth Report on Carcinogens in 2000, IARC (2012) has concluded that there is sufficient evidence in experimental animals for the carcinogenicity of sidestream smoke condensates and for the carcinogenicity of mixtures of mainstream and sidestream tobacco smoke.

\section{Properties}

Environmental tobacco smoke is a complex mixture of thousands of chemicals that are emitted from burning tobacco. Environmental tobacco smoke is the sum of sidestream smoke, mainstream smoke, compounds that diffuse through the wrapper, and exhaled mainstream smoke. Sidestream smoke contributes at least half of the smoke generated (NRC 1986, CEPA 1997). The composition of tobacco smoke is affected by many factors, as discussed in the profile for Tobacco Smoking (above). Although many of the same compounds are present in both mainstream and sidestream smoke, important differences exist. The ratios of compounds in sidestream and mainstream smoke are highly variable; however, there is less variability in emissions from sidestream smoke than in emissions from mainstream smoke, because smoking patterns and cigarette design have a greater impact on the composition of mainstream smoke (CEPA 1997). Sidestream smoke is generated at lower temperatures than is mainstream smoke $\left(600^{\circ} \mathrm{C}\right.$ vs. $\left.900^{\circ} \mathrm{C}\right)$, is produced in an oxygendeficient environment, and is rapidly diluted and cooled after leaving the burning tobacco. Mainstream smoke is generated at higher temperatures in the presence of oxygen and is drawn through the tobacco column. These conditions favor formation of smaller par- 
ticulates in sidestream smoke ( 0.01 to $0.1 \mu \mathrm{m}$ in diameter) than in mainstream smoke ( 0.1 to $1 \mu \mathrm{m})$. Sidestream smoke also typically contains higher concentrations of ammonia (40- to 170-fold), nitrogen oxides (4- to 10-fold), and chemical carcinogens (e.g., benzene, 10-fold; $\mathrm{N}$-nitrosoamines, 6- to-100 fold; and aniline, 30-fold) than does mainsteam smoke (IARC 1986).

A number of chemicals present in environmental tobacco smoke are known or suspected toxicants or irritants with various acute health effects. Prominent among them are the respiratory irritants ammonia, formaldehyde, and sulfur dioxide. Acrolein, hydrogen cyanide, and formaldehyde affect mucociliary function and at higher concentrations can inhibit smoke clearance from lungs (Battista 1976). Nitrogen oxides and phenol are additional toxicants present in environmental tobacco smoke. Over 50 compounds present in environmental tobacco smoke have been identified as known or reasonably anticipated to be human carcinogens, including some naturally occurring radionuclides. Most of these compounds are present in the particulate phase (IARC 1986, CEPA 1997).

\section{Use}

Environmental tobacco smoke is a by-product of smoking and has no industrial or commercial uses. It is used in scientific research to study its composition and health effects. See the profile for Tobacco Smoking (above) for a brief description of the history and uses of tobacco products.

\section{Production}

Environmental tobacco smoke is produced by smoking of various forms of tobacco products. Information on tobacco production is provided in the profile on Tobacco Smoking (above).

\section{Exposure}

Evidence that people in the United States are exposed to cigarette smoke, including environmental tobacco smoke, is provided by the National Health and Nutrition Examination Survey (NHANES). The 1988-1991 NHANES estimated that $90 \%$ of the U.S. population aged 4 years or older had detectable serum levels of cotinine, the primary metabolite of nicotine used as a biomarker for tobaccosmoke exposure (Pirkle et al. 1996). The median (50th-percentile) serum cotinine level among nonsmokers decreased from $0.20 \mathrm{ng} / \mathrm{mL}$ in 1991 to $0.05 \mathrm{ng} / \mathrm{mL}$ in 1999 and $0.017 \mathrm{ng} / \mathrm{mL}$ in the 2013-2014 NHANES (CDC 2001, 2018). An independent nonfederal Task Force on Community Preventive Services, in collaboration with the U.S. Department of Health and Human Services and various public and private partners, recommended strategies to (1) reduce exposure to environmental tobacco smoke (e.g., vis smoking bans and restrictions), (2) stop people from ever smoking (e.g., by increasing tobacco product unit price and multicomponent mass media campaigns), and (3) help people quit smoking (e.g., via multicomponent interventions, including telephone support for persons wishing to stop using tobacco and reducing patient out-of-pocket costs for effective cessation therapies) (CDC 2000).

From its peak in the mid 1960s to 2017, the prevalence of smoking in the United States declined by about 67\% (ALA 2019). Public policies have restricted smoking in buildings and other indoor public places. Nevertheless, environmental tobacco smoke remains an important source of exposure to indoor air contaminants. Although levels of cotinine in nonsmokers exposed to secondhand smoke fell by $44.7 \%$ from 1988 to 2004 (CDC 2010), it has been estimated that 9 million to 12 million children aged six or younger are exposed to environmental tobacco smoke in their homes (EPA 2002).
Because environmental tobacco smoke is a complex mixture, exposure is difficult to measure. Various monitoring methods typically focus on levels of nicotine or respirable suspended particulates in indoor air or cotinine levels in blood, saliva, or urine. Levels of exposure to environmental tobacco have been estimated in many studies as concentrations of respirable suspended particles (particles $<2.5 \mu \mathrm{m}$ in diameter). The average concentrations of respirable suspended particles in these studies generally ranged from 5 to $500 \mu \mathrm{g} / \mathrm{m}^{3}$. Concentrations of respirable suspended particles in homes with one or more smokers were 20 to $100 \mu \mathrm{g} / \mathrm{m}^{3}$ higher than in comparable homes with no smokers (CEPA 1997). Mean nicotine levels in various indoor environments ranged from 0.3 to $30 \mu \mathrm{g} / \mathrm{m}^{3}$. Typical average concentrations in homes with at least one smoker ranged from 2 to $14 \mu \mathrm{g} / \mathrm{m}^{3}$.

Nicotine concentrations measured at workplaces from the mid 1970s to 1991 were similar to those measured in homes; however, maximum values were much higher at workplaces (CEPA 1997). Levels of environmental tobacco smoke in restaurants (measured as mean concentrations of respirable suspended particles and nicotine) were 1.6 to 2.0 times the levels in office workplaces and 1.5 times the levels in residences with at least one smoker. Isolating smokers to a specific section of restaurants was found to afford some protection for nonsmokers, but the best protection resulted from seating arrangements that segregated smokers with a wall or partition. However, nonsmokers in restaurants were still exposed to nicotine and respirable particles. Food servers had higher levels of exposure than diners, even if they worked in nonsmoking sections (Lambert et al. 1993). Levels of environmental tobacco smoke in bars (based on concentrations of carbon monoxide, nicotine, and respirable suspended particles) were 3.9 to 6.1 times the levels in office workplaces and 4.4 to 4.5 times the levels in residences (Siegel 1993). Nicotine levels as high as 50 to $75 \mu \mathrm{g} / \mathrm{m}^{3}$ were measured in bars and on airplanes (before smoking was banned). The highest nicotine concentration $\left(1,010 \mu \mathrm{g} / \mathrm{m}^{3}\right)$ was measured in a car with the ventilation system shut off (CEPA 1997).

\section{Regulations}

\section{Executive Order 13058}

It is the policy of the executive branch to establish a smoke-free environment for Federal employees and members of the public visiting or using Federal facilities and, therefore, the smoking of tobacco products is prohibited in all interior space owned, rented, or leased by the executive branch of the federal government, and in any outdoor areas under executive branch control in front of air intake ducts.

Federal Aviation Authority (FAA, Dept. of Transportation)

Smoking is prohibited on all scheduled flights within the United States.

\section{Guidelines}

National Institute for Occupational Safety and Health (NIOSH, CDC, HHS)

Environmental tobacco smoke is considered a potential occupational carcinogen; exposure should be reduced to the lowest feasible concentration.

\section{References}

ALA. 2008. Trends in Tobacco Use. American Lung Association. http://www.notontobacco.com/media/ files/TREND_TOBACCO_JULY_08-1.pdf.

ALA. 2019. Adult smoking rate by sex, race, and age. American Lung Association. Unpublished data, received 1/30/19.

Battista SP. 1976. Cilia toxic components of cigarette smoke. In Proceedings of the 3rd World Conference on Smoking and Health, New York, NY, 2-5 June 1975. Wynder EL, Hoffmann D, Gori GB, eds. Ashwanden P, coordinating ed. DHEW (NIH) Publication no. 76-1221. Bethesda, MD: U.S. Department of Health, Education, and Welfare. pp. 517-534.

Brownson RC, Alavanja MC, HockET, Loy TS. 1992. Passive smoking and lung cancer in nonsmoking women. Am J Public Health 82(11): 1525-1530.

CDC. 2000. Strategies for reducing exposure to environmental tobacco smoke, increasing tobacco-use cessation, and reducing initiation in communities and health-care systems. A report on recommendations of the Task Force on Community Preventative Services. Morbid Mort Weekly Report 49(RR-12): 1-11.

CDC. 2010. Smoking and Tobacco Use: Secondhand Smoke (SHS). Last updated 1/15/10. http://www.cdc. gov/tobacco/data_statistics/fact_sheets/secondhand_smoke/general_facts/index.htm. 
CDC. 2018. Cotinine. In Fourth National Report on Human Exposure to Environmental Chemicals, Updated Tables, March 2018, vol. 1. Atlanta, GA: U.S. Department of Health and Human Services, Centers for Disease Control and Prevention. pp. 21-23.

CEPA. 1997. Health Effects of Exposure to Environmental Tobacco Smoke. Office of Environmental Health Hazard Assessment, California Environmental Protection Agency. http://www.oehha.org/air/ environmental_tobacco/finalets.html.

EPA. 1992. Respiratory Health Effects of Passive Smoking: Lung Cancer and Other Disorders. EPA/600/690/006F. Washington, DC: U.S. Environmental Protection Agency.

EPA. 2002. Secondhand Smoke/Environmental Tobacco Smoke/Smoke-free Homes. U.S. Environmental Protection Agency. http://www.chiro.org/LINKS/DISCONTINUED/EPA/smokefree.html.

Fontham ET, Correa P, Reynolds P, Wu-Williams A, Buffler PA, Greenberg RS, et al. 1994. Environmental tobacco smoke and lung cancer in nonsmoking women. A multicenter study. JAMA 271(22): 1752-1759. IARC. 1986. Tobacco Smoking. IARC Monographs on the Evaluation of Carcinogenic Risk of Chemicals to Humans, vol. 38. Lyon, France: International Agency for Research on Cancer. 421 pp.

IARC. 2004. Tobacco Smoking and Involuntary Smoking. IARC Monographs on the Evaluation of Carcinogenic Risks to Humans, vol. 83. Lyon, France: International Agency for Research on Cancer. 1452 pp.

IARC. 2012. Second-hand tobacco smoke. In Personal Habits and Indoor Combustions. IARC Monographs on the Evaluation of Carcinogenic Risk of Chemicals to Humans, vol. 100E. Lyon, France: International Agency for Research on Cancer. pp. 213-263.

Kabat GC, Stellman SD, Wynder EL. 1995. Relation between exposure to environmental tobacco smoke and lung cancer in lifetime nonsmokers. Am J Epidemiol 142(2): 141-148.

LambertWE, Samet JM, Spengler JD. 1993. Environmental tobacco smoke concentrations in no-smoking and smoking sections of restaurants. Am J Public Health 83(9): 1339-1341.

NRC. 1986. Environmental Tobacco Smoke. Measuring Exposures and Assessing Effects. National Research Council, Washington, DC: National Academy Press.

Pirkle JL, Flegal KM, Bernert JT, Brody DJ, Etzel RA, Maurer KR. 1996. Exposure of the US population to environmental tobacco smoke: the third National Health and Nutrition Examination Survey, 1988 to 1991. JAMA 275(16): 1233-1240.

Siegel M. 1993. Involuntary smoking in the restaurant workplace. A review of employee exposure and health effects. JAMA 270(4): 490-493.

Stockwell HG, Goldman AL, Lyman GH, Noss Cl, Armstrong AW, Pinkham PA, Candelora EC, Brusa MR. 1992. Environmental tobacco smoke and lung cancer risk in nonsmoking women. J Nat/ Cancer Inst 84(18): 1417-1422.

Wells AJ. 1998. Lung cancer from passive smoking at work. Am J Public Health 88(7): 1025-1029.

Witschi H, Espiritu I, Maronpot RR, Pinkerton KE, Jones AD. 1997a. The carcinogenic potential of the gas phase of environmental tobacco smoke. Carcinogenesis 18(11): 2035-2042.

Witschi H, Espiritu I, Peake JL, Wu K, Maronpot RR, Pinkerton KE. 1997b. The carcinogenicity of environmental tobacco smoke. Carcinogenesis 18(3): 575-586.

\section{Smokeless Tobacco}

CAS No.: none assigned

Known to be a human carcinogen

First listed in the Ninth Report on Carcinogens (2000)

\section{Carcinogenicity}

The oral use of smokeless tobacco is known to be a human carcinogen based on sufficient evidence of carcinogenicity from studies in humans.

\section{Cancer Studies in Humans}

Smokeless tobacco has been shown to cause cancer of the oral cavity (IARC 1985, 1987, Gross et al. 1995). Cancer of the oral cavity has been associated with the use of both chewing tobacco and snuff, which are the two main forms of smokeless tobacco used in the United States. Tumors often arise at the site where the tobacco is placed. Since smokeless tobacco was first listed in the Ninth Report on Carcinogens in 2000, the International Agency for Research on Cancer has concluded that there is sufficient evidence in humans that exposure to smokeless tobacco causes cancer of the esophagus and pancreas, in addition to cancer of the oral cavity (IARC 2012).

\section{Studies on Mechanisms of Carcinogenicity}

Smokeless tobacco products contain nitrosamines that are carcinogenic to animals, including 4-( $N$-nitrosomethylamino)-1-(3-pyridyl)- 1-butanone (NNK) and $N$-nitrosonornicotine (NNN), which are listed in the Report on Carcinogens as reasonably anticipated to be human carcinogens. The oral use of smokeless tobacco is estimated to be the greatest external source of human exposure to nitrosamines. Nitrosamines are metabolically hydroxylated to form unstable compounds that bind to DNA. Extracts of smokeless tobacco have been shown to cause mutations in bacteria and mutations and chromosomal aberrations in mammalian cells. Furthermore, cells in oral-cavity tissue from smokeless tobacco users have been shown to contain more chromosomal damage than those from nonusers (IARC 1985).

\section{Cancer Studies in Experimental Animals}

Evidence for the carcinogenicity of smokeless tobacco in experimental animals is inadequate. Some studies have provided some evidence that snuff or extracts of snuff caused tumors of the oral cavity in rats (Johansson et al. 1989); however, most studies had deficiencies in study design. The International Agency for Research on Cancer (IARC 1985, 1987) also concluded that the evidence for the carcinogenicity of smokeless tobacco in experimental animals was inadequate.

\section{Properties}

Chewing tobacco consists of the tobacco leaf with the stem removed and various sweeteners and flavorings, such as honey, licorice, or rum. Snuff consists of the entire tobacco leaf (dried and powdered or finely cut), menthol, peppermint oil, camphor, and/or aromatic additives such as attar of roses or oil of cloves (IARC 1985).

Tobacco contains more than 2,500 chemical constituents, including chemicals applied to tobacco during cultivation, harvesting, and processing. The major chemical groups include aliphatic and aromatic hydrocarbons, aldehydes, ketones, alcohols, phenols, ethers, alkaloids, carboxylic acids, esters, anhydrides, lactones, carbohydrates, amines, amides, imides, nitrites, $\mathrm{N}$ - and $\mathrm{O}$-heterocyclic compounds, chlorinated organic compounds, and at least 35 metal compounds. Smokeless tobacco products contain many known or reasonably anticipated human carcinogens, such as volatile and nonvolatile nitrosamines, tobacco-specific $N$-nitrosamines (TSNAs), polynuclear aromatic hydrocarbons, and polonium-210. The concentrations of carcinogenic TSNAs are at least twice those found in other consumer products (Brunnemann et al. 1986). TSNAs present in tobacco, including NNK and NNN, are formed from nicotine and other tobacco alkaloids. The concentrations of NNK and NNN, the most carcinogenic of the TSNAs, are high enough in tobacco that their total estimated doses to long-term snuff users are similar in magnitude to the total doses required to produce cancer in laboratory animals (Hecht and Hoffmann 1989).

\section{Use}

Tobacco was widely used by native populations throughout both North and South America by the time the first European explorers arrived in the late 1400s and early 1500s. Over the next few centuries, tobacco use spread to Europe, Africa, China, and Japan. Snuff use was introduced to North American colonists at Jamestown, Virginia, in 1611. Tobacco chewing among American colonists began in the early 1700s, but was not widely accepted until the 1850s (IARC 1985).

Snuff was the most popular form of tobacco in both Europe and the United States before the 1800s. At that time, the finely ground tobacco was primarily sniffed through the nose. The current practice in the United States is to place a small pinch between the lip and gum or cheek and gum (IARC 1985). Moist snuff is the only smokeless tobacco product that has shown increased sales in the United States in recent years. This product is considered the most dangerous form of smokeless tobacco (NCI 1991, USDA 2001). In the three 
leading brands of snuff, which accounted for $92 \%$ of the U.S. market, concentrations of nicotine and TSNAs were significantly higher than in the fourth and fifth most popular brands (Hoffman et al. 1995). The highest per-capita consumption of snuff in the United States occurred from 1910 to 1920 at $0.5 \mathrm{lb}$, but had decreased to $0.15 \mathrm{lb}$ by 1979. After the U.S. Department of Agriculture reclassified several chewing tobacco products as snuff in 1982, the male per-capita consumption of snuff increased to $0.26 \mathrm{lb}$ and remained at 0.2 to $0.3 \mathrm{lb}$ through 2000 (IARC 1985, USDA 2001).

Peak consumption of chewing tobacco in the United States for persons aged 15 years and over was $4.1 \mathrm{lb}$ in 1900; consumption gradually declined to $0.5 \mathrm{lb}$ by 1962 . However, per-capita consumption for males aged 18 and over ranged from 1.05 to 1.34 lb between 1966 and 1983 (IARC 1985). Per-capita consumption for males declined to $0.8 \mathrm{lb}$ in 1991 , increased to $1.04 \mathrm{lb}$ in 1992, and then declined gradually to $0.9 \mathrm{lb}$ by 2000 (USDA 2001).

\section{Production}

Five major U.S. manufacturers of smokeless tobacco products control $99 \%$ of the market. The largest company controls over $40 \%$ of the total smokeless tobacco market and about $75 \%$ of the moist snuff market (FTC 2001).

Annual U.S. production of snuff increased from 4 million pounds in 1880 to over 40 million pounds in 1930. Production remained steady through 1950 at 36 to 44 million pounds and then declined to 24 million pounds by 1980 (IARC 1985). From 1986 to 2016, annual U.S. sales of moist snuff steadily increased from 36 million pounds to over 58 million pounds, while sales of Scotch snuff or dry snuff products declined from 8.1 million pounds to $869,000 \mathrm{lb}$ (FTC 2001). In 2017, U.S. exports of snuff and snuff flours totaled 578,000 lb, and exports totaled 2 million pounds (USITC 2019).

Chewing tobacco products include plug, moist plug, twist/roll, and loose leaf. Total U.S. production declined from 67.4 million kilograms (148.6 million pounds) in 1931 to 29.4 million kilograms (64.8 million pounds) in 1962. Production then rose to 48.1 million kilograms (106.0 million pounds) in 1980, but has since declined steadily. From 1931 to 1980 , the market share of plug tobacco declined from $51 \%$ to $16 \%$, while the share of loose-leaf tobacco increased from $41 \%$ to $68 \%$ (IARC 1985). From 1986 to 2016, sales of loose-leaf chewing tobacco declined from 65.7 million pounds to 17.1 million pounds, and sales of plug and twist chewing tobacco combined declined from 8.8 million pounds to 470,000 lb (FTC 2001). In 2017, the United States imported 1 million pounds of chewing tobacco and exported 183,000 lb (USITC 2019).

\section{Exposure}

Individuals who use smokeless tobacco are exposed primarily by absorption through the oral or nasal mucosa and by ingestion. Occupational exposure to tobacco may occur through skin contact, inhalation of dust, and ingestion of dust during processing and manufacturing. Many smokeless tobacco users are exposed during most of their working hours, and some use these products 24 hours per day (IARC 1985).

Consumption of smokeless tobacco products showed a resurgence in the late 1970s, after decades of decline. Increased use of these products was particularly dramatic among adolescent boys, increasing by 250\% or more between 1970 and 1985 (NCI 1991). The estimated number of smokeless tobacco users ranged from 7 million to 22 million in the early 1980s (IARC 1985) and was estimated at 10 million in 2001 (UMN 2001) and 8.6 million in 2017 (SAMHSA 2018). In 2017, $4.4 \%$ of adults aged 18 and over used smokeless tobacco, including an estimated 9.9 million men and 1.1 million women. About $67 \%$ of snuff users and $45 \%$ of chewing-tobacco users reported daily use. The prevalence of use was highest (8.2\%) in men aged 18 to 24 (CDC 1993). State-specific estimates of the prevalence of smokeless tobacco use among adults aged 18 and over in 2014 ranged from approximately $1.4 \%$ (Hawaii) to $8.8 \%$ (Wyoming); use was much higher among men (2.3\% to $16.5 \%)$ than women ( $0.4 \%$ to $3.4 \%)$ (Nguyen et al. 2016). In 2001 , it was estimated that the 10 million U.S. users of smokeless tobacco included 3 million under the age of 21 (UMN 2001).

\section{Regulations}

\section{Federal Trade Commission (FTC)}

All smokeless tobacco products and advertisements for smokeless tobacco must contain a label statement on the risks of smokeless tobacco.

Advertising of smokeless tobacco products on radio and television is banned.

\section{References}

Brunnemann KD, Prokopczyk B, Nair J, Ohshima H, Bartsch H. 1986. Laboratory studies on oral cancer and smokeless tobacco. Banbury Rep 23: 197-213.

CDC. 1993. Use of smokeless tobacco among adults_-United States, 1991. Morbid Mortal Wkly Rep 42(14): 263-266.

CDC. 1998. State-specific prevalence among adults of current cigarette smoking and smokeless tobacco use and per capita tax-paid sales of cigarettes—United States, 1997. Morbid Mortal Wkly Rep 47(43): 922-926. FTC. 2018. Federal Trade Commission Smokeless Tobacco Report for 2016. U.S. Federal Trade Commission. https://www.ftc.gov/reports/federal-trade-commission-cigarette-report-2016-federal-tradecommission-smokeless-tobacco.

Gross AJ, Lackland DT, Tu DS. 1995. Oral cancer and smokeless tobacco: Literature review and metaanalysis. Environ Int 21(4): 381-394.

Hecht SS, Hoffmann D. 1989. The relevance of tobacco-specific nitrosamines to human cancer. Cancer Surv 8(2): 273-294.

Hoffman D, Djordjevic M, Fan J, Zang E, Glynn T, Connolly G. 1995. Five leading U.S. commercial brands of moist snuff in 1994: Assessment of carcinogenic N-nitrosamines. J Natl Cancer Inst 87: 1862-1869.

IARC. 1985. Tobacco Habits Other than Smoking: Betel-Quid and Areca-Nut Chewing; Some Related Nitrosamines. IARC Monographs on the Evaluation of Carcinogenic Risk of Chemicals to Humans, vol. 37. Lyon, France: International Agency for Research on Cancer. 291 pp.

IARC. 1987. Tobacco products, smokeless. In Overall Evaluations of Carcinogenicity: An Updating of IARC Monographs Volumes 1 to 42. IARC Monographs on the Evaluation of Carcinogenic Risk of Chemicals to Humans, suppl 7. Lyon, France: International Agency for Research on Cancer. pp. 357-359.

IARC. 2012. Smokeless tobacco. In Personal Habits and Indoor Combustions. IARC Monographs on the Evaluation of Carcinogenic Risk of Chemicals to Humans, vol. 100E. Lyon, France: International Agency for Research on Cancer. pp. 265-318.

Johansson SL, Hirsch JM, Larsson PA, Saidi J, Osterdahl BG. 1989. Snuff-induced carcinogenesis: effect of snuff in rats initiated with 4-nitroquinoline $N$-oxide. Cancer Res 49(11): 3063-3069.

NCI. 1991. Smokeless Tobacco or Health: An International Perspective. Smoking and Tobacco Control Monograph 2. National Cancer Institute. http://cancercontrol.cancer.gov/TCRB/monographs/2/index.html. Nguyen KH, Marshall L, Brown S, Neff L. 2016. State-specific prevalence of current cigarette smoking and smokeless tobacco use among adults — United States, 2014. Morbid Mortal Wkly Rep 65(39): 1045-1051. SAMHSA. 2018. Results from the 2017 National Survey on Drug Use and Health: Detailed Tables. Substance Abuse and Mental Health Services Administration. https://www.samhsa.gov/data/sites/default/files/ cbhsq-reports/NSDUHDetailedTabs2017/NSDUHDetailedTabs2017.pdf.

UMN. 2001. Smokeless Tobacco Facts. University of Minnesota Division of Periodontology. http://www1. umn.edu/perio/tobacco/smokeless.html.

USDA. 2001. Tobacco: Situation and Outlook Report. TBS-249. U.S. Department of Agriculture Economic Research Service. http://usda.mannlib.cornell.edu/usda/ers/TBS//2000s/2001/TBS-04-05-2001.pdf.

USITC. 2019. USITC Interactive Tariff and Trade DataWeb. United States International Trade Commission. http://dataweb.usitc.gov/scripts/user_set.asp and search on HTS no. 2403992040, 2403990040, 2403992030, 2403990030. 